\title{
NOVEL CEMENT CURING TECHNIQUE BY USING CONTROLLED \\ RELEASE OF CARBON DIOXIDE COUPLED WITH NANOSILICA
}

\author{
Taha M. Jassam ${ }^{1, *}$, Kow Kien-Woh ${ }^{2}$, Jason ng yang-zhi ${ }^{1}$, Bonnie Lau ${ }^{1}$, \\ M.M.M.Yaseer ${ }^{1}$
}

1 Civil Engineering Department, Faculty of Engineering, Technology and Built Environment, UCSI University, Kuala Lumpur 56000, Malaysia

2 Department of Chemical and Environmental Engineering, Faculty of Science and Engineering, The University of Nottingham Ningbo China, Ningbo 315100, China.

\begin{abstract}
Nanotechnology has attracted a lot of interest in the modification of building materials involving nanoparticles. Among the nanoparticles available, the incorporation of nanosilica draws intense attention due to the similarity of its chemical composition with cement and its pozzolanic properties. In this work, the potential capability to utilise $\mathrm{CO} 2$ in improving cement composites properties through carbonation acceleration mechanism was explored. In this study, various type of nano silica was used as a CO2 carrier and incorporated into cement mortar design with different amount of carbonated silica loading, ranging from $0.55 \mathrm{wt} \%$ to $2.42 \mathrm{wt} \%$ and cured in water and ambient air condition. The aim of this study is to examine the effects on the compressive strength of nano-silica impregnated with $\mathrm{CO} 2$ and incorporated into cement mortar. From the results, it was found that at $1.89 \%$ silica loading, the hydrophilic silica mortar (HSAM) samples can achieve the highest compressive strength of $34.1 \mathrm{MPa}$ at 7 days and $40.7 \mathrm{MPa}$ at 28 days, with a percentage gain of $+38.06 \%$ and $+17.29 \%$ respectively as compared to blank samples. However, the incorporation of silica for more than $1.89 \mathrm{wt} \%$ resulted in a negative effect on the
\end{abstract}


compressive strength gain of HSAM samples. By the incorporation of $2.42 \mathrm{wt} \%$, the samples showed a significant drop in compressive strength of $-21.46 \%$ at 7 days and $17.29 \%$ at 28 days. The results proved that nano-silica coupled with $\mathrm{CO} 2$ can accelerate curing of cement mortar by means of carbonation.

*Keyword: Nano-silica, carbonation, cement curing, accelerated curing, compressive strength

\section{Introduction}

Nanotechnology appears to be regarded as the significant aspect for construction materials, nanophase composites allow future advancement in concrete durability as well as a significant improvement in compressive strength of concrete materials [1]. The role of nano silica particularly has achieved beneficial effects in enhancing the compressive strength of cement due to the pozzolanic reaction that contributes to a denser microstructure with the aid of carbonation reaction [2]. However, the utilisation of silica aerogels for insulating buildings is limited following by the high manufacturing costs of aerogels. A novel process of creating silica aerogels was discovered in 2005, which involves extracting silica from rice husks as an alternative to sand, thus leading to manufacturing costs of silica aerogel being reduced tremendously by $80 \%$ [3]. Other studies also confirmed that incorporation of nanomaterials leads to higher carbonation degree of cementitious materials thus improving the overall concrete properties. Nano-silica possesses astounding characteristics which include high specific surface area and porosity, low density as well as being exceptional in terms of heat insulation [4]. Nano-silica such as silica are also proven to have effective $\mathrm{CO} 2$ capturing abilities. Hence in this study, it is aimed 
to promote accelerated curing during the initial curing stages of cementitious material by using nano-silica as $\mathrm{CO} 2$ carrier.

Nano-silica is used as a $\mathrm{CO} 2$ carrier and incorporated into cement mortar with different loading and cured in different condition. The compressive strength of samples will be examined to evaluate the effect of such incorporation of nanomaterials. By incorporating nano-silica to develop high carbonation degree in construction materials, it reduces the curing and construction time and increases the service life of future buildings.

Carbonation strengthens concrete by reducing the total porosity of concrete via formation of the $\mathrm{CaCO} 3$ volume [1]. Porosity development is created by the disintegration of cement phases. Due to the predomination of water condensation in smaller pores, $\mathrm{CaCO} 3$ precipitation occurs more preferentially in the pore solution [5]. The total pore volume per gram of paste eventually decreasing the porosity on the surface slowly moving into the inner part of the concrete [6].

Calcium-Silicate-Hydrate also known as C-S-H is a chain consist of silica that held together by $\mathrm{Ca} 2+$ ions and $\mathrm{OH}$ - ions where it is the most intricate transformation of the main cement paste phase. At the phase where $\mathrm{Ca} 2+$ content is reduced during carbonation phase in the pores, $\mathrm{C}-\mathrm{S}-\mathrm{H}$ will release $\mathrm{Ca} 2+$ to compensate the low $\mathrm{Ca} 2+$ content. This give progressively alter the C-S-H composition therefore result in a smaller $\mathrm{Ca} / \mathrm{Si}$ ratio. Ultimately, when the $\mathrm{Ca} / \mathrm{Si}$ ratio falls to below than 1.0 where the $\mathrm{pH}$ stands around 10, it will change to silica gel [6]. In spite of this, some Ca content will dependably remain in the silica gel. In a study reported by Bary and Sellier (2004), it is assumed that the remaining of $\mathrm{C}-\mathrm{S}-\mathrm{H}$ in the complete carbonated zone having a 
$0.85 \mathrm{CaO} / \mathrm{SiO}$ is much denser in the microstructure compared to 1.65 in the uncarbonated zone.

Further studies show that the formation of silica gel due to $\mathrm{C}-\mathrm{S}-\mathrm{H}$ decomposition is closely related to pore structure coarsening. As an outcome of the pozzolanic reaction of fly ash attributable to low portlandite content in blended cement pastes, the coarsening of pore structure is more defined [7].

A dissolution stage is seen on the initial sealing stage of the pores using that the carbonation reaction is not a gradual stable process rather by phases that clogs the porosity on the initial phase [8]. In the same study, Rimmelé et al. (2008) illustrated the porosity gradient in carbonated Portland cement using image analysis of Backscattered Scanning Electron (BSE). At the exposed surface, porosity decreased significantly followed by a small increment at the carbonated zone where dissolution front occurs and porosity stayed with small gradient fluctuation in the internal portion of the cement.

Rate of carbonation is the most pronounced when the relative humidity of the surrounding environment is around 50\% - 70\% stated by Atis (2004). Concrete with high internal moisture demonstrates much lower carbonation rate due to the fact that diffusion of $\mathrm{CO} 2$ turns out to be difficult when the pore solution is well-saturate. Rate of carbonation likewise reduces at a lower internal moisture level as a result of inadequate water dispersion in the pores for the reaction with water to take place [9]. Type of binder materials is considered as an essential element in determining the dissolution of the pore system. In such, when fly ash is utilised as a fractional cement replacement, where the initial $\mathrm{CaO}$ content accessible for hydration diminished, 
resulting in lower $\mathrm{Ca}(\mathrm{OH}) 2$ content. Silica in fly ash further reacts with $\mathrm{Ca}(\mathrm{OH}) 2$ resulting in the lesser amount of $\mathrm{Ca}(\mathrm{OH}) 2$ remains in the concrete. This greatly affects the formation of $\mathrm{CaCO} 3$ the product of $\mathrm{Ca}(\mathrm{OH}) 2$ reacts with $\mathrm{CO} 2$ and water. The expected outcome of $\mathrm{Ca}(\mathrm{OH}) 2$ and fly ash does not occur due to less accessibility of $\mathrm{Ca}(\mathrm{OH}) 2$ for the hydration process in fly ash [10].

In a study carried out by Sagüés et al. (1997), the carbonation depth increased as the Water-to-Cement ratio increased from 0.37 to 0.50 . This possibly due to the availability of diffused $\mathrm{CO} 2$ exhibit in the interconnected capillary pore solution. They also investigated that at a given $\mathrm{W} / \mathrm{C}$ ratio carbonation depth increased as the cement replacement fly ash increased from $20 \%$ - 50\% [11]. The concentration of CO2 proved to be one of the most effective variables to increase the rate of carbonation using accelerated carbonation method. Accelerated carbonation can be achieved by curing concrete in a high concentration of $\mathrm{CO} 2$ environment such as a $\mathrm{CO} 2$ induction chamber. With the right level of relative humidity and temperature range, rate of carbonation up to 3000 times than normal atmosphere exposure can be achieved [12].

$\mathrm{CO} 2$ infusion also known as the accelerated carbonation of cement-based materials has become a common practice in conducting research. In the recent years, utilising accelerated carbonation technique which capable of reaching carbonation rates of concrete materials up to 3000 times higher than the normal atmospheric carbonation could significantly improve the compressive strength properties, surface hardness, chemical resistance and durability of concrete materials by densification and pore refinement of the concrete matrix [13]. On research carried out by Shaik Hussain et al. (2015) it is observed that with the increase of carbonation rate, the volume of 
permeable voids has decreased, which in turns increases the compressive strength, flexural strength and carbonation depth [12].

Concrete carbonation initiates corrosive environment in steel reinforcement of concrete. Such condition is favourable for chloride ion attack through corrosion despite that a passive oxide barrier film is formed [14]. Steel reinforcement can corrode through a reduction in concrete $\mathrm{pH}$ close to the steel reinforcement bars. In the research done by Pourbaix (1994), reviewed that corrosion begins at the degree of $\mathrm{pH}$ of 10.4 or lesser on the passive oxide barrier film on the surface of steel reinforcement bar of concrete. At the point where strong alkaline content of having $\mathrm{pH}$ value of 10.4 or lesser, it indicates sufficient flow of water and oxygen into the pores within concrete subjected to carbonation [15].

Generally, $\mathrm{CaCO} 3$ and water are the products formed through carbonation reaction [16]. Parrott (1984) reported that sufficient oxygen and moisture is essential to corrosion by neutralisation. Steel rust usually comes into sight resulting in concrete defects such as cracking in such a way that volume expands from 2.5 to 7 times which deteriorates structure's serviceability [17]. In this event, it is significant to evaluate the carbonation depth from the standpoint of concrete serviceability. In a study done by Ho Jae Lee et al. (2012) to investigate the carbonation depth of paste, mortar and concrete matrix of different Water-to-Cement ratio, via phenolphthalein indicator method. 
Aerogels are classified as a diverse of open-porous particles known as mesopores most notably known for their pore diameters in the nano-range and with an extremely low density of $\sim 0.1 \mathrm{~g} / \mathrm{cm}^{3}$ [18]. Silica aerogels are identified to having, per unit volume of any solid, one of the highest surface areas with spherical molecule clusters forming fractal-like links. The chains produce a very absorbent solid construct (equal to or greater than $95 \%$ porosity) that surrounds air occupied apertures that average in length to about $20 \mathrm{~nm}-40 \mathrm{~nm}$, offering favourable sustenance for CO2 capturing capability [19]. Cui et al. (2011) in recent years incorporated silica aerogels that are aminemodified for $\mathrm{CO} 2$ capture function by utilizing amino-propyl groups onto the surface of the silica and managed to accomplish an adsorption capacity of $6.97 \mathrm{mmol} / \mathrm{g}$ at $25^{\circ} \mathrm{C}$ in a dry and humid $10 \% \mathrm{CO} 2$ stream [20]. Based on the term 'carbon capturing', carbonated aerogels can be effectively applied as aggregates in the concrete industry. Following a study by Nick Linneen et al. (2013) involving the examination of the CO2 capturing capability with the application of particulate silica aerogels that are immobilized with tetraethylenepentamine (TEPA), it can be deduced that hydrophilic aerogel sorbents with $80 \%$ TEPA loading reached the largest adsorption capacity of $6.1 \mathrm{mmol} / \mathrm{g}$ and also displayed outstanding cyclic stability which indicates a functioning $\mathrm{CO} 2$ adsorption capacity of $5.1 \mathrm{mmol} / \mathrm{g}$ over 10 cycles [21]. Natural carbonation is regarded to be a very slow process, thus by incorporating carbon capturing aerogels, accelerated carbonation reaction can be achieved during critical stages of cement curing [22].

Several researches have been conducted in the past proving the effectiveness of silica aerogels incorporation in cement-based materials as high thermal resistance. This remarkably plays an essential role in world energy consumption by utilizing energy efficient construction materials. In a study reported by Forood Torabian et al. (2016) 
indicated that with the addition of low dosages of nano silica (NS) significantly improved the concrete compressive strength in the case of W/C ratio of 0.65 [23]. The 7 days compressive strength exhibited improvement from $30.3 \mathrm{MPa}$ to $39.5 \mathrm{MPa}$ for 1.5\% NS addition due to the accelerating effect on the initial cement hydration. Following this study, the presence of additional nano silica produces a higher amount of C-S-H, thus improving the compressive strength of concrete. In another research done by Tao Gao et al. (2014) to study the incorporation of silica aerogel particles into concrete matrix known as Aerogel Incorporated Concrete, it is observed that the thermal and mechanical properties of AIC are greater compared to normal concrete materials with the right formulation and chemical additives [24]. As for mechanical properties, AIC behaves differently in terms of achieving greater compression and flexure strength from the other concrete materials such as Expanded Polystyrene Concrete (EPS) as shown in Figure. 1, though they are more analogous to the EPS concrete than the normal concrete materials, indicating the similarity between EPS beads and aerogel granules as lightweight aggregates [25].

However, with high aerogels content particularly known to effectively yield the lowest thermal conductivities are also indirectly accountable for low compressive strength properties without any supporting parameters such as plasticizer and chemical additives [26]. A recent study manifested the utilization of Insulation Mortar UltraHigh Performance Concrete (I-UHPC) formulation in enhancing structural properties based on aerogel composites. Due to the low packing effectiveness and effective binding properties of aerogel, a drastic drop in mechanical properties was observed in the samples especially in high aerogel loadings without the use of any additives [27]. 


\section{Materials and Methods}

\subsection{Material}

Type 1 Normal Ordinary Portland Cement with a particle density of $3.11 \mathrm{~g} / \mathrm{cm}^{3}$ was used with the physical and chemical compositions provided in Table 1 that satisfy Ordinary Portland Cement specifications in Type 1 according to the ASTM C150.

Table 1: General Constituents of Type 1 Ordinary Portland Cement.

\begin{tabular}{|l|c|}
\hline \multicolumn{1}{|c|}{ Constituent } & Weight (\%) \\
\hline Lime $(\mathrm{CaO})$ & $60.0-67.0$ \\
Silica $\left(\mathrm{SiO}_{2}\right)$ & $17.0-25.0$ \\
Alumina $\left(\mathrm{Al}_{2} \mathrm{O}_{3}\right)$ & $3.0-8.0$ \\
Iron Oxide $\left(\mathrm{Fe}_{2} \mathrm{O}_{3}\right)$ & $0.5-6.0$ \\
Magnesia $(\mathrm{MgO})$ & $0.1-4.0$ \\
Sulfur Trioxide $\left(\mathrm{SO}_{3}\right)$ & $1.0-3.0$ \\
Soda and/or Potash $\left(\mathrm{Na}_{2} \mathrm{O}+\mathrm{K}_{2} \mathrm{O}\right)$ & $0.5-1.3$ \\
\hline
\end{tabular}

Standard graded silica sand composed of almost entirely of silica $\left(\mathrm{SiO}_{2}\right)$ with a particle density of $1.52 \mathrm{~g} / \mathrm{cm}^{3}$ was used as fine aggregates in compliance to the standard sand requirement in ASTM C778 for the mortar mix. The particle size distribution of the silica sand used is shown in Table 2 below.

Table 2 : Particle size distribution of silica sand.

\begin{tabular}{|l|cccc|}
\hline Grading & $1.18 \mathrm{~mm}$ (No. 16) & $850 \mu \mathrm{m}$ (No. 20) & $600 \mu \mathrm{m}$ (No. 30) & $425 \mu \mathrm{m}$ (No. 40) \\
\hline Passing (\%) & 100 & - & 98 & 71 \\
\hline
\end{tabular}

Hydrophobic silica aerogel and Hydrophilic Commercial silica fume were used in this experimental work. During the preparation stage, the silica aerogel was ensured to have a particle size of below $2 \mathrm{~mm}$ by gently crushed the silica aerogel using a 
hammer. Aerogel incorporation technique was based on the nature of the aerogel as below:

- Hydrophobic nature - silica aerogel with hydrophobic nature are previously mix with any commercial anionic surfactant to lower the surface tension (or interfacial tension) of the aerogel, then water is added gradually to obtain a uniform aqueous mixture together with the fine aggregate (silica sand). Lastly, cement is added and mixed well using the mortar mixer.

- Hydrophilic nature - surfactant are not required and dry mixing process involving cement, sand and silica aerogel are applied first using a $600 \mathrm{~W}$ Blender to ensure homogeneity of the materials. Water is then added gradually into the blender to premix the dry materials and to avoid silica aerogel from escaping and continued using the mortar mixer.

\subsection{Methods}

\subsubsection{Method of $\mathrm{CO}_{2}$ Infusion into Silica}

Before adding the silica into the mortar mix, the silica was pre-carbonated with $\mathrm{CO} 2$ in a laboratory setting to infuse and impregnate CO2 in the pores. Dry ice (99\% CO2 purity) was used to introduce $\mathrm{CO} 2$ molecules into the silica in a lab desiccator. Before starting the infusion process, the lab desiccator was cleaned thoroughly to remove any foreign materials that may affect the infusion process.

Firstly, the required silica for each sample batching according to the design mix proportion was placed into the lab desiccator. Next, 200g of dry ice was weighed and placed at the top of the steel plate inside the lab desiccator as shown in Figure. 1. The 
infusion process was carried out for 2 hours to ensure that the aerogel pores were well saturated with $\mathrm{CO} 2$ molecules. In order to minimize the loss of $\mathrm{CO} 2$ in the silica aerogel, the carbonated silica aerogel was kept in the lab desiccator until the silica aerogel is needed for specimen mixing. Note that the mixing of carbonated silica aerogel with the mortar must be within a total elapsed time of fewer than 120 seconds right after the carbonated aerogel is removed from the lab desiccator.

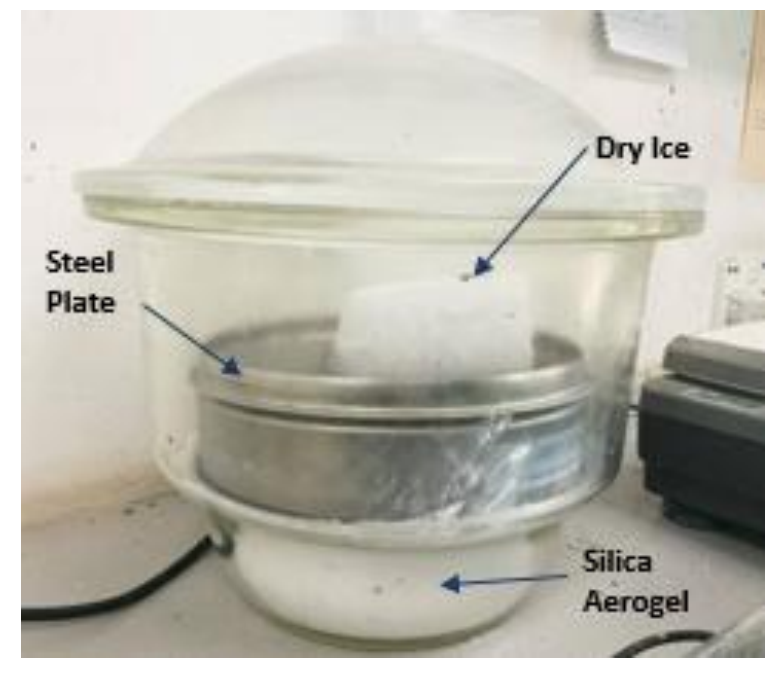

Figure. 1: $\mathrm{CO}_{2}$ Infusion of silica in desiccator.

\subsubsection{Method in Preparing Samples}

The design mix proportions shown in Table 3 were obtained according to Clause 10.1 Composition of Mortars outlined in ASTM C109/C109M. The material proportion for the design mix is " 1 part of cement to 2.75 of sand by weight". The cement mortar specimens were designed and fabricated with a constant W/C ratio of 0.6 as indicated to be the most optimum $\mathrm{W} / \mathrm{C}$ ratio to promote a higher degree of carbonation reaction. The design mix proportion criteria are shown below;

- Type 1 Normal Ordinary Portland Cement (particle density of $3.11 \mathrm{~g} / \mathrm{cm}^{3}$ )

- Standard silica sand (particle density of $1.52 \mathrm{~g} / \mathrm{cm}^{3}$ ) 
- Silica Aerogel (bulk density of $\sim 6 \mathrm{~g} / 100 \mathrm{ml}$ )

- Cement to Sand Ratio = 1:2.75

- Water to Cement Ratio $=0.6$

- Silica Aerogel loading: M2 (0.55wt\%), M3 (0.84wt\%), M4 (1.09wt\%), wtM5 (1.36wt\%), M6 (1.63wt\%), M7 (1.89wt\%), M8 (2.19wt\%), M9 (2.42wt\%), M10 $(2.68 \mathrm{wt} \%)$.

- Each sample are design for a batch of 12 specimens of $50 \times 50 \times 50 \mathrm{~mm}$ mold, 3 for water curing 7 days, 3 for water curing 28 days, 3 for air curing 7 days and 3 for air curing 28 days.

- $5 \mathrm{wt} \%$ wastage adopted for all materials.

- All Design Mix Proportions are in accordance with ASTM C109/C109M.

\begin{tabular}{|c|c|c|c|c|c|c|}
\hline Sample Batch & Cement (g) & Sand (g) & $\begin{array}{c}\text { W/C } \\
\text { Ratio }\end{array}$ & $\begin{array}{c}\text { Water } \\
(\mathbf{m l})\end{array}$ & $\begin{array}{c}\text { Aerogel } \\
\text { Loading } \\
(\mathbf{g})\end{array}$ & $\begin{array}{c}\text { Aerogel } \\
\text { Loading } \\
\text { (vol \%) }\end{array}$ \\
\hline $\begin{array}{c}\text { Control } \\
\text { (Blank) }\end{array}$ & 1052.0 & 2887.0 & 0.6 & 630.0 & 0 & 0 \\
\hline $\begin{array}{c}\text { Control 3 } \\
(\text { Aerogel with } \\
\text { no CO })\end{array}$ & 1052.0 & 2887.0 & 0.6 & 630.0 & 37.8 & 0.84 \\
\hline $\begin{array}{c}\text { Control 6 } \\
\left(\begin{array}{c}\text { Aerogel with } \\
\text { no CO })\end{array}\right.\end{array}$ & 1052.0 & 2887.0 & 0.6 & 630.0 & 75.6 & 1.63 \\
\hline $\begin{array}{c}\text { Control 9 } \\
(\text { Aerogel with } \\
\text { no CO } \mathrm{CO}_{2}\end{array}$ & 1052.0 & 2887.0 & 0.6 & 630.0 & 113.4 & 2.42 \\
\hline $\mathrm{M} 2$ & 1052.0 & 2887.0 & 0.6 & 630.0 & 25.2 & 0.55 \\
\hline $\mathrm{M} 3$ & 1052.0 & 2887.0 & 0.6 & 630.0 & 37.8 & 0.84 \\
\hline
\end{tabular}




\begin{tabular}{|c|c|c|c|c|c|c|}
\hline M4 & 1052.0 & 2887.0 & 0.6 & 630.0 & 50.4 & 1.09 \\
\hline M5 & 1052.0 & 2887.0 & 0.6 & 630.0 & 63.0 & 1.36 \\
\hline M6 & 1052.0 & 2887.0 & 0.6 & 630.0 & 75.6 & 1.63 \\
\hline M7 & 1052.0 & 2887.0 & 0.6 & 630.0 & 88.2 & 1.89 \\
\hline M8 & 1052.0 & 2887.0 & 0.6 & 630.0 & 100.8 & 2.19 \\
\hline M9 & 1052.0 & 2887.0 & 0.6 & 630.0 & 113.4 & 2.42 \\
\hline $\begin{array}{l}\text { \# Note that each sample batch has 12 specimens. } \\
\text { \# Note that aerogel loading for each sample batch is equivalent to total of 12 specimens. }\end{array}$ \\
\hline
\end{tabular}

Table 3: Design Mix Proportion Table

Before material mixing, all required materials were measured according to the design mix proportion. The sample batch was divided into half to accommodate the limited space of the mixer bowl and to avoid excessive spillage of materials during mixing. Firstly, dry mixing involving cement, sand and silica aerogel was applied first using a $600 \mathrm{~W}$ Blender to ensure homogeneity of the dry materials is achieved as shown in Figure. 2. Water was then added gradually into the blender to premix the dry materials and to avoid the silica aerogel from escaping. Next, the materials were transferred into the mixing bowl. To set up the mortar mixing, the paddle and the mixing bowl were positioned in the mortar mixer accordingly and covered with a wet cloth to prevent loss of silica aerogel during mixing as shown in Figure. 3.

The mixer was started at a slow speed of about $140 \pm 5 \mathrm{rev} / \mathrm{min}$ for 30 seconds. Next, the mixer was stopped and let the mortar stand for 90 seconds. During the first 15 seconds of this interval, any mortar that may have collected on the side of the bowl 
was scraped down. The mixer was then changed to medium speed about $285 \pm 10$ rev/min followed by 90 seconds rest period and 60 seconds final mixing at medium speed. Material mixing is conducted for at least 5 minutes according to ASTM C30506 using mortar mixer as shown in Figure. 2.

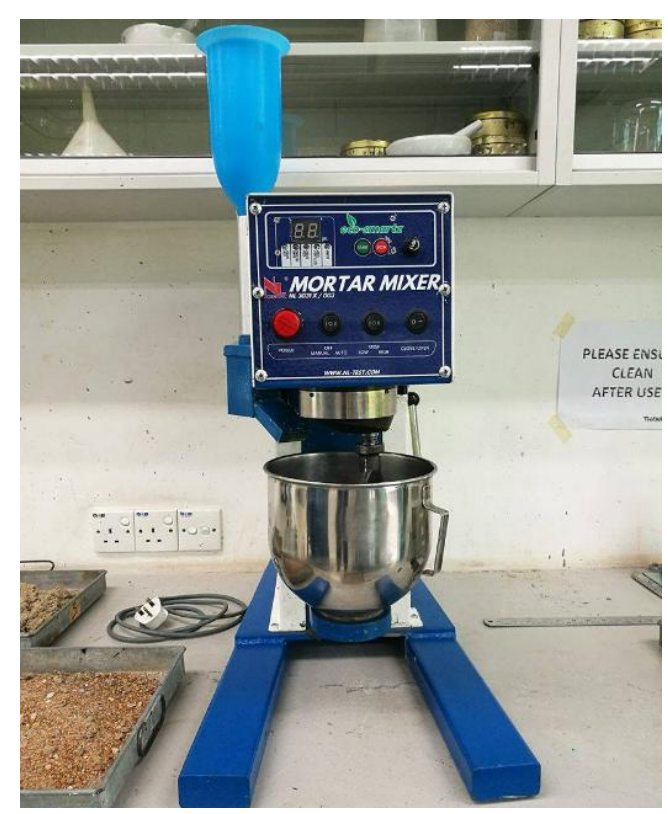

Figure. 2: Electrical Mortar Mixer.

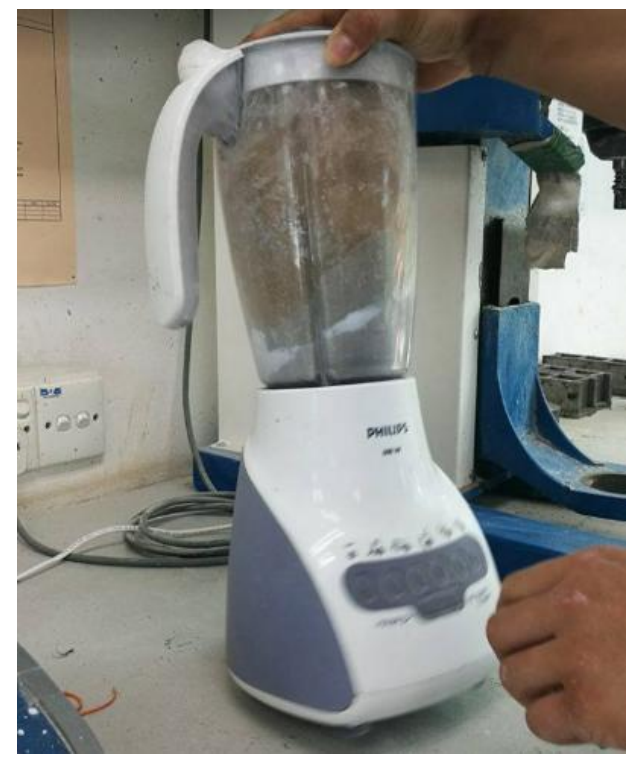

Figure. 3: Dry Mixing using 600W Blender involving cement, sand and silica 
After homogenous cement mortar is achieved, the cement mortar specimens were casted in " $50 \mathrm{~mm} \times 50 \mathrm{~mm} \times 50 \mathrm{~mm}$ " steel moulds according to the procedures outlined in ASTM C109/C109M. All steel moulds were placed on a flat surface and grease was applied on the faces of mould and the base plate using any cloth to prevent the mortar specimens from sticking to the mould. Then, the moulds were filled with mortars by using a trowel in three different layers for compaction purposes within a total elapsed time of fewer than 90 seconds. On each layer, the mortar was tamped at least 30 times in 4 rounds about 10 seconds with a standard tamping rod as shown in Figure. 4. The surface of the mortar that protrudes slightly above the top part was smoothed by dragging the flat side of the trowel once along the mould. All casted specimens were covered wet cloth to prevent initial moisture loss from evaporation in room condition for at least 24 hours before demolding Figure. 5. After demolding, the mortar specimens were labelled and immediately placed in either water or ambient air respectively for 7 days and 28 days curing process.

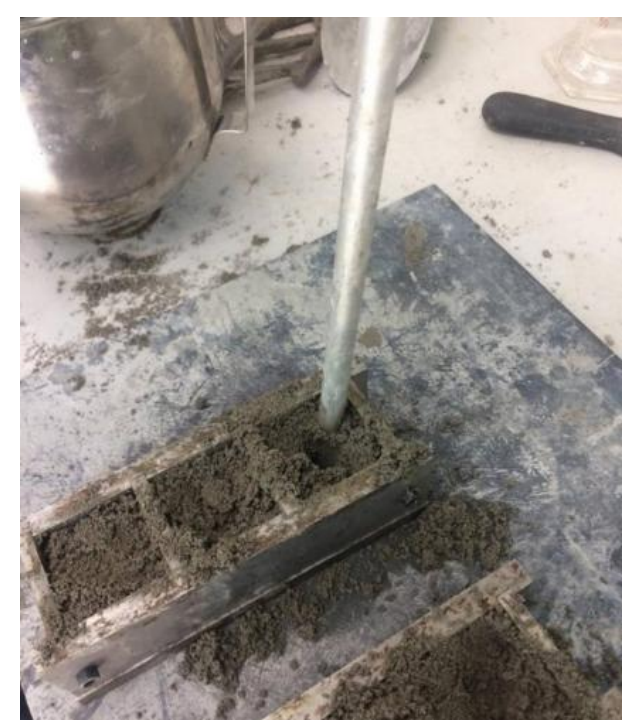

Figure. 4 : The mortar was tamped in 3 layers during casting. 


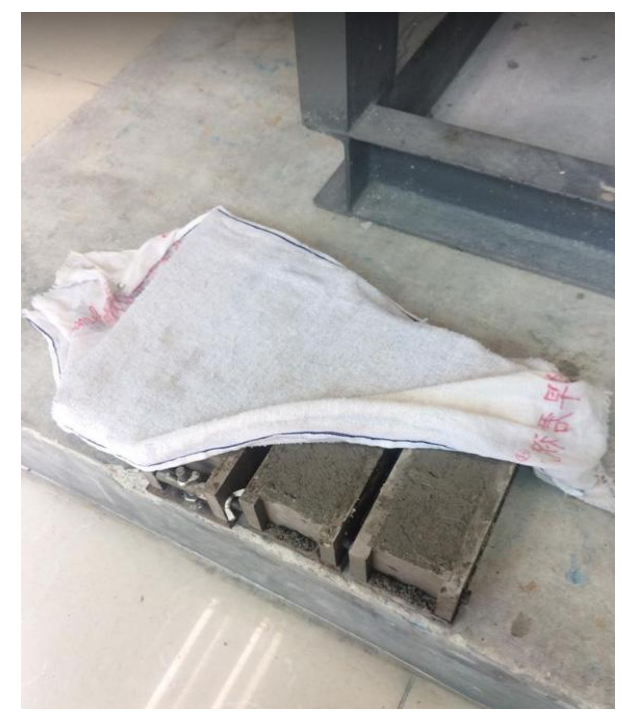

Figure. 5: Casted specimens were covered with a wet cloth for 24 hours.

\subsubsection{Curing Condition}

The curing of the specimens was conducted in water or natural ambient air for both 7 days curing and 28 days curing stage according to ASTM C192/C 192M. In water, the specimens were placed in a water storage tank (Figure. 6) exposed to free air temperature in lab settings .In ambient air, the specimens were placed in a sheltered rain-free environment outdoor settings exposed to condition free air temperature in lab settings Figure 7. The experiment was designed to explore the influence of carbonation curing with the aid of water hydration in water and without the hydration reaction in ambient air on the degree of carbonation and compressive strength properties of the aerogel incorporated cement mortar specimens. 


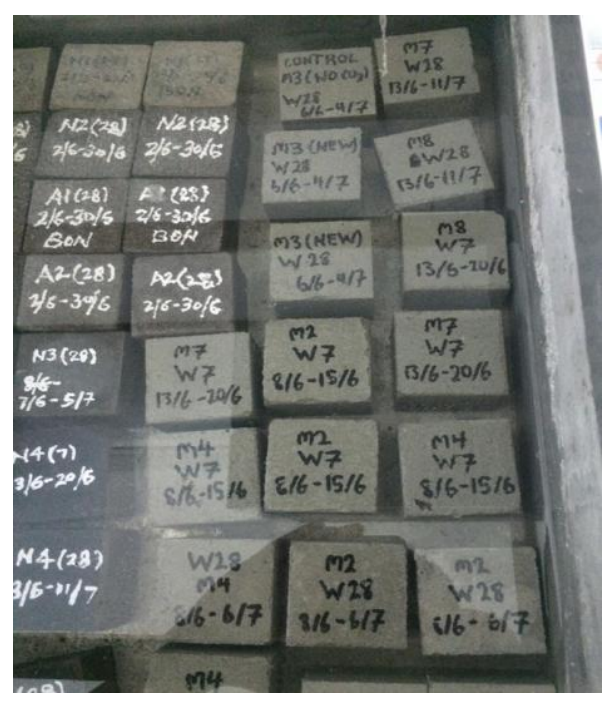

Figure. 6: Water curing

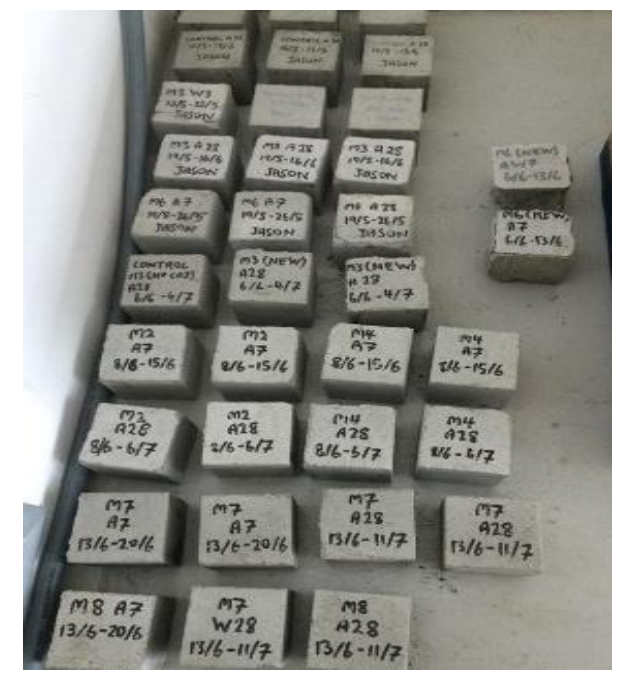

Figure. 7: Ambient air curing

\subsubsection{Compressive Strength Test}

All specimen was wiped using a dry cloth to remove excessive moisture on the specimen's surface and any loose sand grains were removed from the specimen before placing on the testing. Prior to loading, the specimen was carefully placed on the testing machine in the centre of the bearing plate with the position of specimen is 
perpendicular to the direction of the applied load Figure. 8. The load rate was set at $900 \mathrm{~N} / \mathrm{s}$ to the specimen until the sample failed.

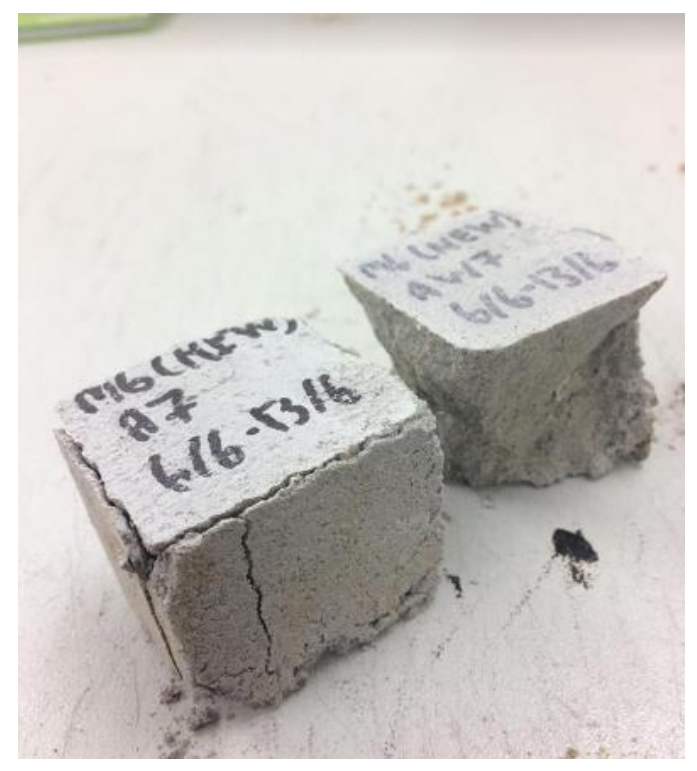

Figure. 8: Failed Specimen.

\section{Results and Discussion}

\subsection{Comparison of samples incorporated with silica aerogel and silica fume without $\mathrm{CO}_{2}$ impregnation}

The compressive strength of hydrophobic silica aerogel and silica fume mortar samples were tested at the age of 7 days for $3 g$ (M3) and $6 \mathrm{~g}$ (M6) silica loadings in water curing and air curing condition. With the different nature of the silica used in this experiment, there is an obvious comparison between both materials when incorporated in the cement matrix. Physically, hydrophobic silica aerogel shows minor segregation at the edge of Trial M3 specimen due to its water repelling effect shown in Figure. 9 (a). The hydrophobicity of silica aerogel causes the cement, sand and aerogel to form into different layers during initial curing without bonding to each other further developed segregation of materials as exemplified by S. Ng et al. (2015) [28]. On the 
other hand, the hydrophilic silica fume of Trial M3 shows better consistency during mixing and forms a homogenous mix shown in Figure. 9 (b). This may indicate a better compressive strength results compared to hydrophobic silica aerogel specimens.
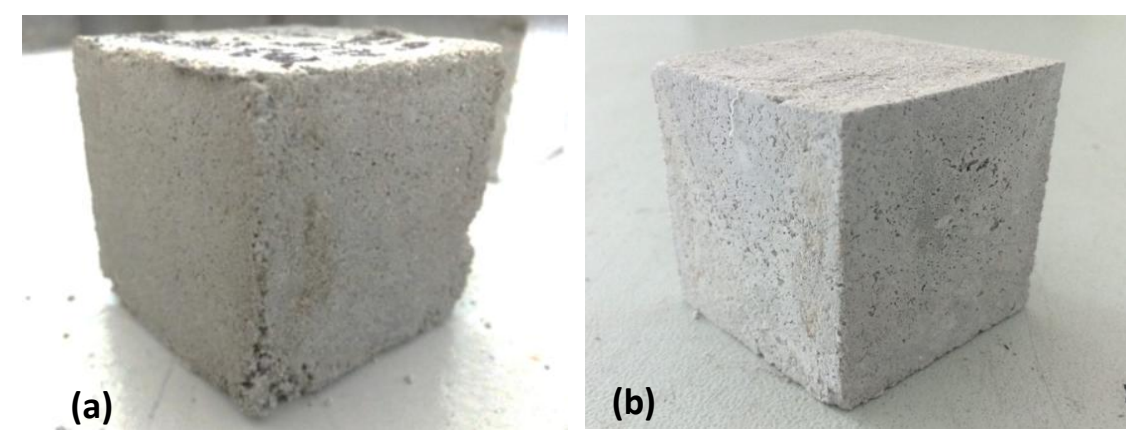

Figure. 9.: Physical condition of silica aerogel incorporated mortars at $3 \mathrm{~g}$ loading. (a) Trial M3 Hydrophobic silica aerogel mortar shows material segregation. (b) Trial M3 Hydrophilic silica aerogel mortar shows homogenous mix with no segregation observed.

Subsequently, at $6 \mathrm{~g}$ (M6) of silica aerogel loading, segregation is more severe using hydrophobic silica aerogel as shown in Figure. 10 (a). During the demolding process, silica aerogel sample shows minor cracking on the edges due to severe segregation of the materials. On the other hand, samples with silica fume show better physical properties with no segregation and cracks are observed during the demolding process as shown in Figure. 10 (b).
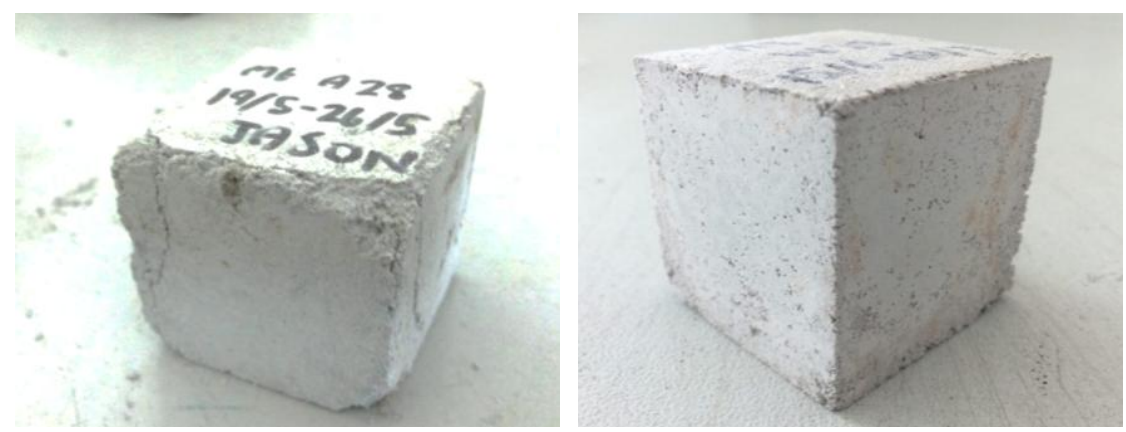
Figure. 10. Physical condition of silica aerogel incorporated mortars at $6 \mathrm{~g}$ loading. (a) Trial M6 Hydrophobic silica aerogel mortar shows severe material segregation.

(b) Trial M6 Hydrophilic silica aerogel mortar shows no segregation

According to Figure.11, the 7 days compressive strength of the trial hydrophilic silica fume mortar samples in water curing increased significantly as compared to the hydrophobic aerogel mortar samples. It signifies that the silica fume can mix well with the cement mortar while hydrophobic aerogel was unable to create a homogenous mix with the mortar due to its water repelling effect and therefore results in drop in the compressive strength. As for the compressive strength at 7 days air curing as shown in Figure 12, the compressive strength of the silica fume mortar samples increased significantly as compared to the hydrophilic aerogel mortar samples. From the results, the margin of compressive strength attainability of air-cured mix is acceptable in comparison with slightly higher margin in water-cured mix samples.

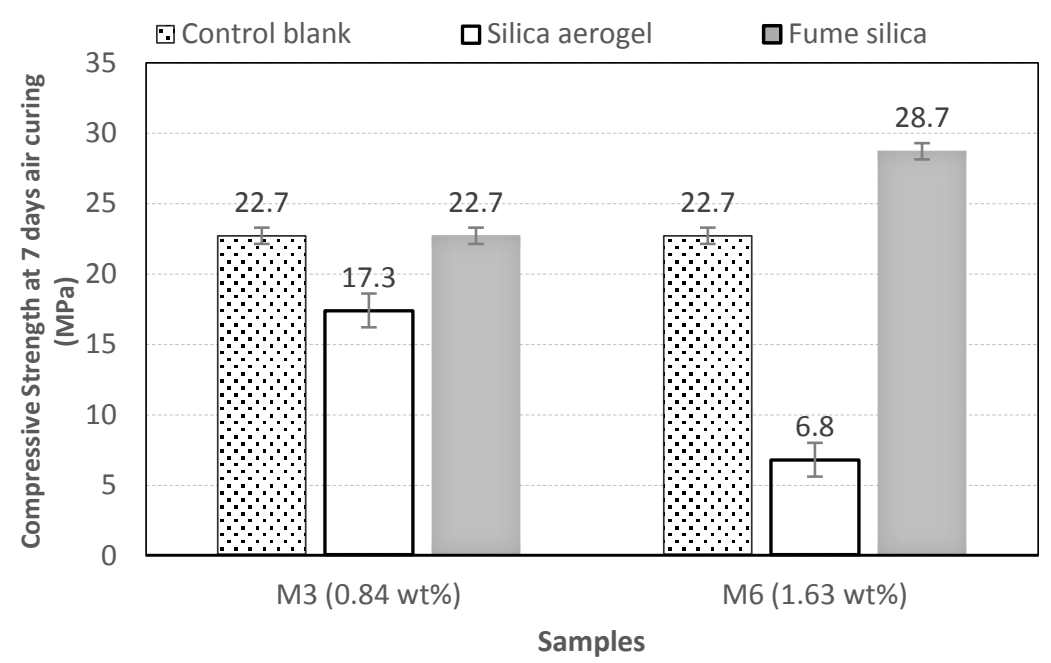

Figure. 11: Compressive Strength at 7 days water curing of M3 and M6 samples. 


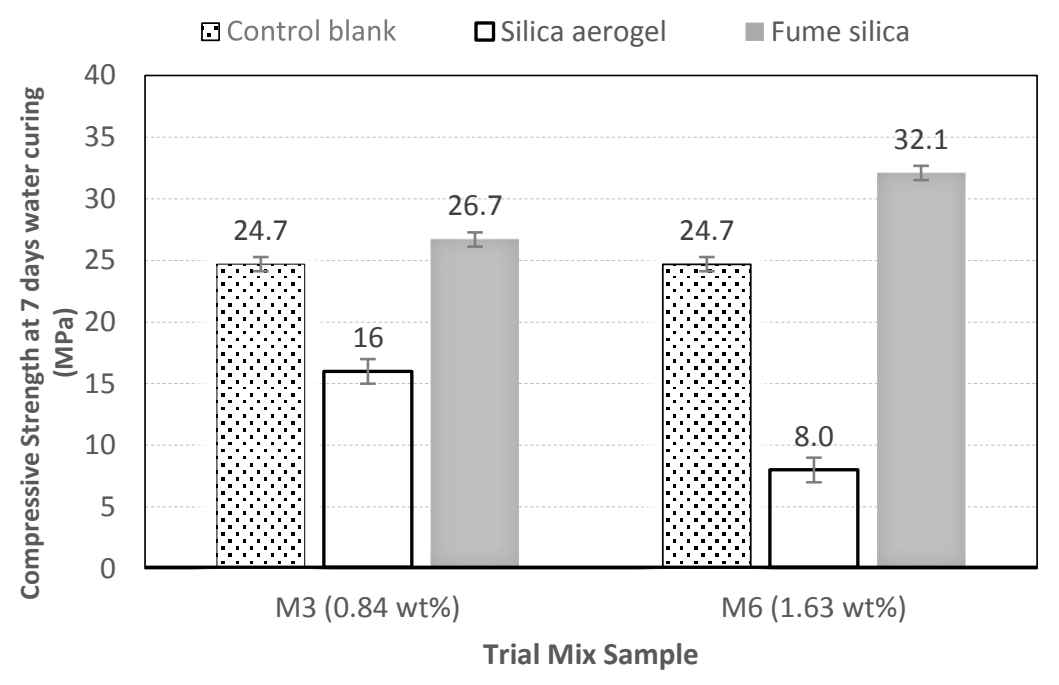

Figure. 12: Compressive Strength at 7 days air curing of M3 and M6 samples.

The compressive strength results in trial experimentation concluded that silica fume shows a significant positive effect in terms of compressive strength gain whereas hydrophobic silica aerogel shows a drastic drop in compressive strength. From the physical observation, it is notable that hydrophobic silica aerogel mortars develop severe segregation of materials due to its water repelling effect that causes the cement, sand and aerogel to form into different layers during the initial curing process that eventually reduced the overall compressive strength of the mortar. On the other hand, silica fume proves to have better mixing consistency with the cementitious materials with stronger bonds formed and the overall compressive strength of the mortar can be increased significantly. Due to these reasons, the following sections are focused only focused on mortar samples incorporated with silica fume.

\subsection{Effect of $\mathrm{CO}_{2}$ impregnation}

Figure. 13 and 14 show the effect of $\mathrm{CO} 2$ impregnation on the compressive strength of various cement samples after 7 and 28 days of curing. Based on Figure. 13, either water cured or air cured samples impregnated with $\mathrm{CO} 2$, the compressive strength of 
samples increased drastically after 7 days of curing using 0.84 and $1.63 \%$ of silica loading.

The samples contained silicFigure. 13 and 14 show the effect of $\mathrm{CO} 2$ impregnation on the compressive strength of various cement samples after 7 and 28 days of curing. Based on Figure. 13, either water cured or air cured samples impregnated with $\mathrm{CO} 2$, the compressive strength of samples increased drastically after 7 days of curing using 0.84 and $1.63 \%$ of silica loading.

The samples contained silica fume only without $\mathrm{CO} 2$ impregnation did not show any beneficial effects in terms of compressive strength gain with only a slight increment on M3 and M6 compared to their corresponding blank samples. The increment attained can be due to the presence of additional silica aerogel produces a higher amount of $\mathrm{C}-\mathrm{S}-\mathrm{H}$ in the mortars thus improving the compressive strength of mortars which supports the literature studied by Forood Torabian et al. (2016) [23]. Compared to the $\mathrm{CO} 2$ impregnated samples, $\mathrm{M} 3$ has an improvement of $8.10 \%$ and a significant improvement of $32.39 \%$ was obtained in M6 due to the accelerated carbonation process induced by the availability of $\mathrm{CO} 2$ molecules in the silica fume pores.

The most significant increase is observed in CO2 impregnated samples with M6, where compressive strength increased by $22.6-28.2 \%$ as compared samples with silica fume only. This is strong evidence that the compressive strength increased solely due to $\mathrm{CO} 2$ impregnation while only gaining little influence resulted from the addition of silica fume. However, such an advantage of $\mathrm{CO} 2$ impregnation diminished when higher silica loading $(2.42 \%)$ was used in M9. The similar trend was observed after 28 days of curing. Though CO2 impregnation still showing advantage after 28 days, the gain of compressive strength was only $9.6-11.3 \%$ higher than samples that contained 
silica fume only. In other words, the $\mathrm{CO} 2$ impregnation may be useful to accelerate strength development in the initial state of curing, but would not add many advantages to its final strength after long curing.

a fume only without $\mathrm{CO} 2$ impregnation did not show any beneficial effects in terms of compressive strength gain with only a slight increment on M3 and M6 compared to their corresponding blank samples. The increment attained can be due to the presence of additional silica aerogel produces a higher amount of $\mathrm{C}-\mathrm{S}-\mathrm{H}$ in the mortars thus improving the compressive strength of mortars which supports the literature studied by Forood Torabian et al. (2016) [23]. Compared to the CO2 impregnated samples, M3 has an improvement of $8.10 \%$ and a significant improvement of $32.39 \%$ was obtained in M6 due to the accelerated carbonation process induced by the availability of $\mathrm{CO} 2$ molecules in the silica fume pores.

The most significant increase is observed in $\mathrm{CO} 2$ impregnated samples with M6, where compressive strength increased by $22.6-28.2 \%$ as compared samples with silica fume only. This is strong evidence that the compressive strength increased solely due to $\mathrm{CO} 2$ impregnation while only gaining little influence resulted from the addition of silica fume. However, such an advantage of $\mathrm{CO} 2$ impregnation diminished when higher silica loading $(2.42 \%)$ was used in M9. The similar trend was observed after 28 days of curing. Though CO2 impregnation still showing advantage after 28 days, the gain of compressive strength was only $9.6-11.3 \%$ higher than samples that contained silica fume only. In other words, the $\mathrm{CO} 2$ impregnation may be useful to accelerate strength development in the initial state of curing, but would not add many advantages to its final strength after long curing. 

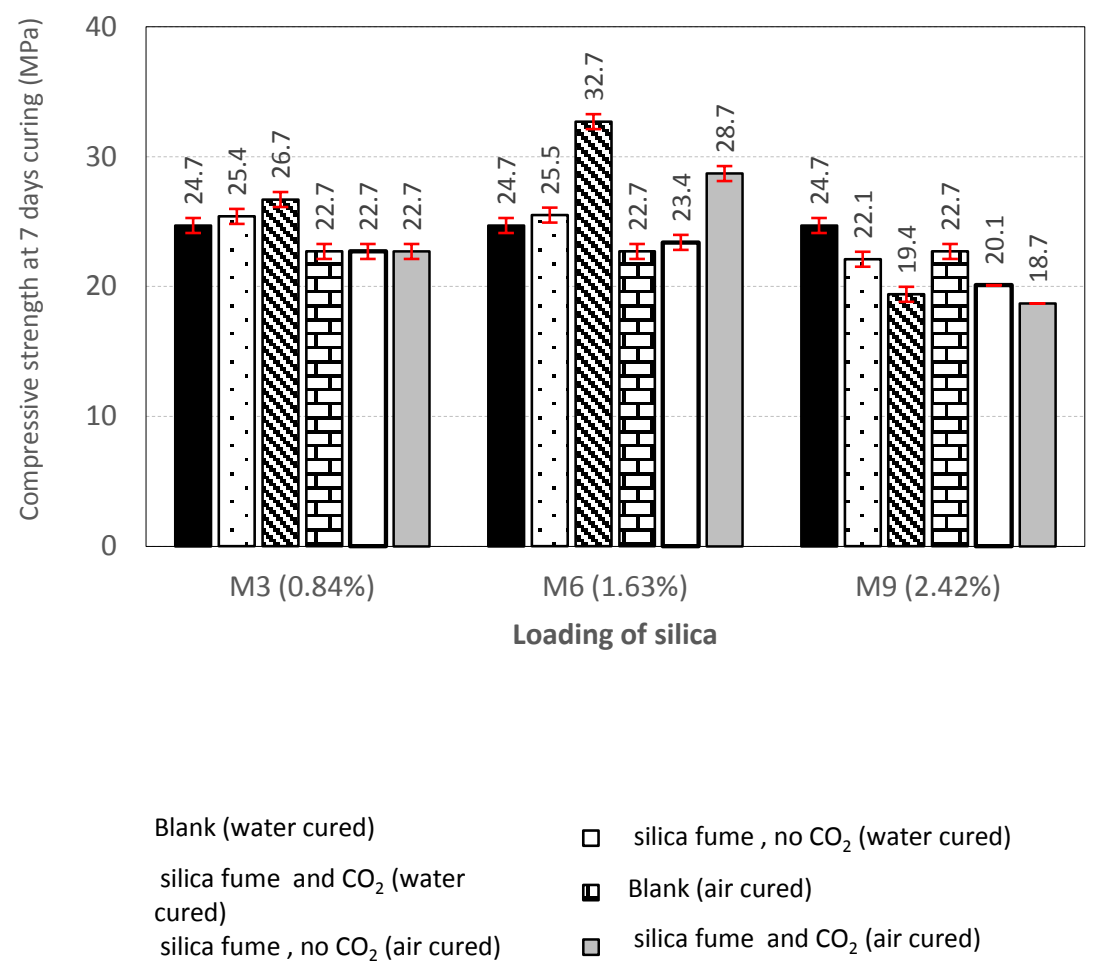

Figure. 13: Effect of $\mathrm{CO}_{2}$ impregnation on compressive strength after 7 days of curing

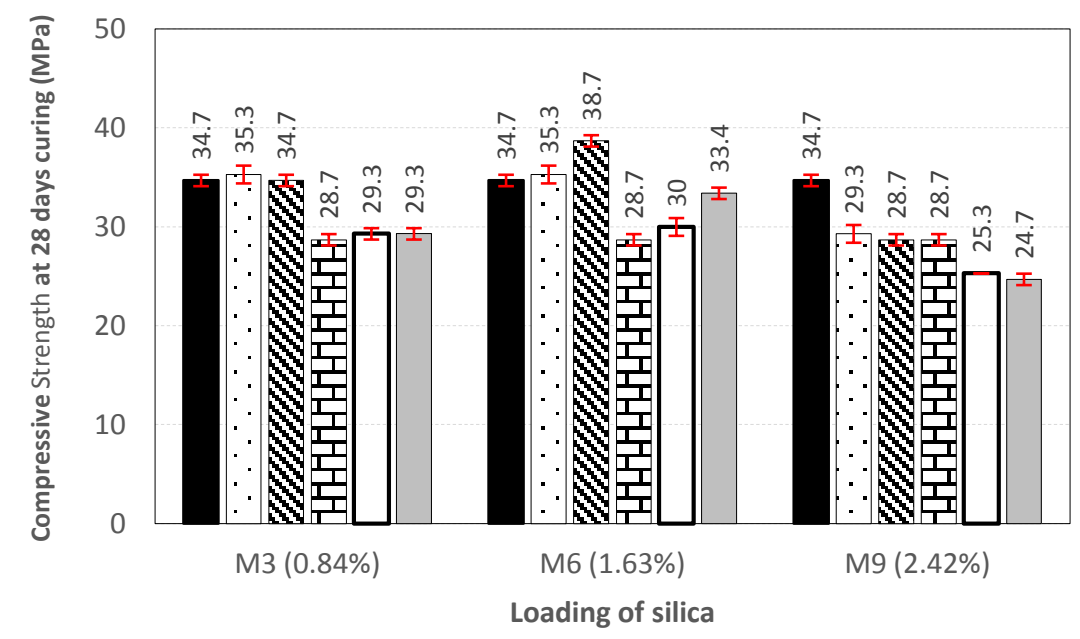

- Control Blank Water

$\square$ Control (Aerogel with No CO2) Water

\$ HSAM Water

घ Control Blank Air

$\boldsymbol{\square}$ Control (Aerogel with No CO2) Air

$\square$ HSAM Air

Figure. 14: Effect of $\mathrm{CO}_{2}$ impregnation on compressive strength after 28 days of curing 
Samples containing carbonated silica aerogel fillers positive effect on the compressive strength gain due to the accelerated carbonation process induced by the availability of $\mathrm{CO} 2$ molecules in the silica aerogel pores. At the same time, this study proved that samples containing uncarbonated silica fume did not lead to significant compressive strength gain with only slight increment (less than 5\%). Both water-cured and aircured $\mathrm{CO} 2$ impregnated samples showed a drop in compressive strength at M9 with $2.42 \%$ silica loading indicates that the effective binder present is insufficient to bind the matrix together due to high loading of silica. Based on these findings, it is noteworthy that the maximum compressive strength can only be achieved with the optimum amount of silica fume added, which will be discussed in section 3.3 and 3.4.

\subsection{Effects of silica loading to water-cured samples}

Based on the results in Figure. 15 and 16, it can be observed that the compressive strength of samples increased almost linearly from M3 to M7 by $8.10 \%, 10.53 \%$, $24.30 \%, 32.39 \%$, and $38.06 \%$ respectively as compared to the blank sample. From the outcomes, it is notable that silica fume particles can be combined fairly well with the cement mortar prior before and after adding water as exemplified in the study done by T. Gao et al. (2014) [24]. These results also manifested that during the initial curing process in water, the $\mathrm{CO} 2$ stored in the silica fume is able to induce accelerated carbonation process during the initial cement hydration whereby the pozzolanic reaction occurred more rapidly due to the availability and uniform distribution of $\mathrm{CO} 2$. In spite of this, M2 (0.55\%) sample did not show any beneficial effects in terms of compressive strength gain due to a small dosage of silica fume. M8 and M9 sample 
showed a drop in compressive strength, where M9 decreased by $-21.5 \%$ as compared to the control sample. This is mainly due to high fume loading leads to lesser effective binders in the matrix. With fume loading of $2.42 \%$ in M9, the binder to non-binder ratio drops whereby the binder present is not sufficient to bind the matrix together leading to a prominent drop in the compressive strength.

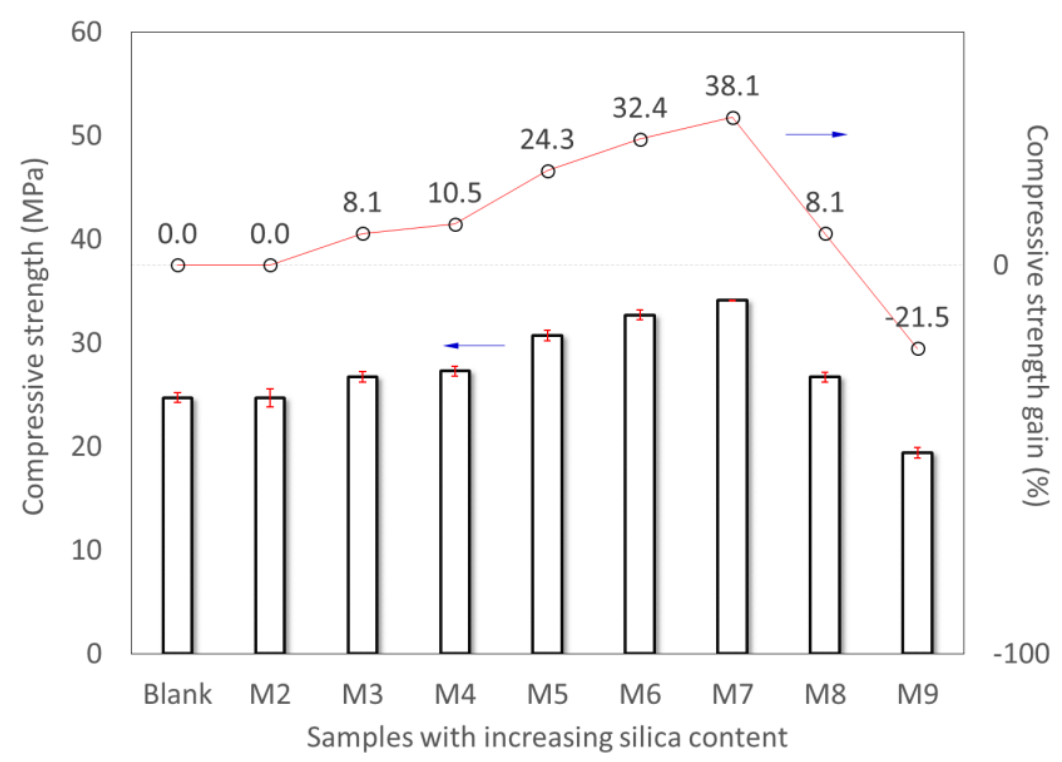

Figure. 15 Effect of silica loading to compressive strength of $\mathrm{CO}_{2}$ impregnated samples after 7 days in water curing.

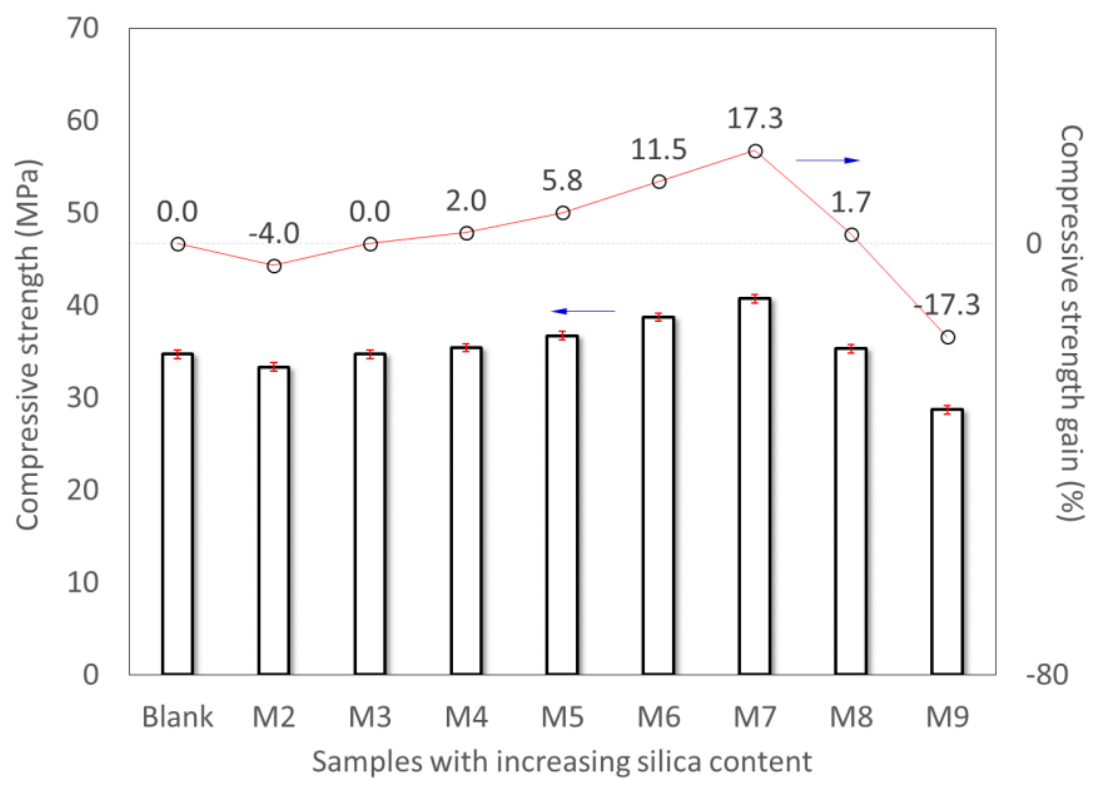


Figure. 16 Effect of silica loading to compressive strength of $\mathrm{CO}_{2}$ impregnated samples after 28 days in water curing

Subsequently at 28 days compressive strength in water curing as shown in Figure. 16, it can be observed that the compressive strength of HSAM increased almost linearly from M4 to M7 by $2.02 \%, 5.76 \%, 11.53 \%$ and $17.29 \%$ respectively as compared to the control sample. As compared to HSAM M7 at 7 days with the highest compressive strength gain of $38.06 \%$, the compressive strength gain at 28 days is less significant with the highest at M7 with $17.29 \%$. This can be due to the effect of the initial carbonation induced by the silica aerogel diminished gradually after 7 days of the initial curing process. In spite of this, M2 and M3 sample did not show any beneficial effects in terms of compressive strength gain due to a small dosage of silica aerogel. M8 and M9 sample showed a drop in compressive strength, where M9 decreased by $17.29 \%$ as compared to the blank sample. Generally, increased in aerogel loading leads to a decrease in the number of effective binders present thus affecting the overall compressive strength as stated in the study done by S. Ng et al. (2015).

\subsection{Effects of silica loading to water-cured samples.}

On the other hand, according to the results at 7 days compressive strength in air curing as shown in Figure. 17, the compressive strength gain increased from M4 to M7 by $6.17 \%, 8.81 \%, 26.43 \%$ and $35.39 \%$ respectively as compared to the blank sample. The outcomes are similar to water cured samples, where silica fume particles can be combined fairly well with the cement mortar prior before and after adding water. These results also manifested that the $\mathrm{CO} 2$ stored in the silica fume able to induced accelerated carbonation process during the initial curing in ambient air condition 
without the aid of water hydration. The margin of compressive strength attained by the air-cured sample is acceptable in comparison with slightly higher strength observed in the water-cured sample due to the absence of water hydration in air-cured samples. However, M2 has slightly lower compressive strength compared to blank and M3 did not show any beneficial effects in terms of compressive strength gain due to a small dosage of silica fume. M8 and M9 sample showed a similar negative trend in compressive strength, where M9 decreased by $-17.62 \%$ as compared to the blank sample. This is mainly due to high fume loading leads to lesser effective binders in the matrix.

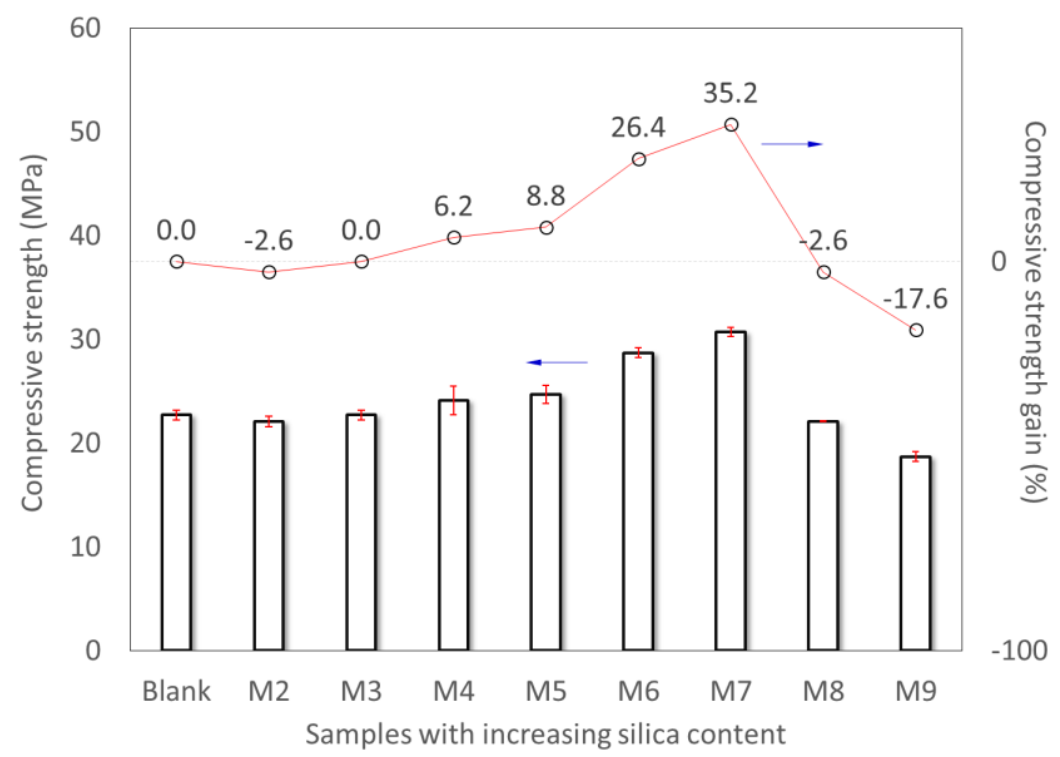

Figure. 17 Effect of silica loading to compressive strength of $\mathrm{CO}_{2}$ impregnated samples after 7 days in air curing. 


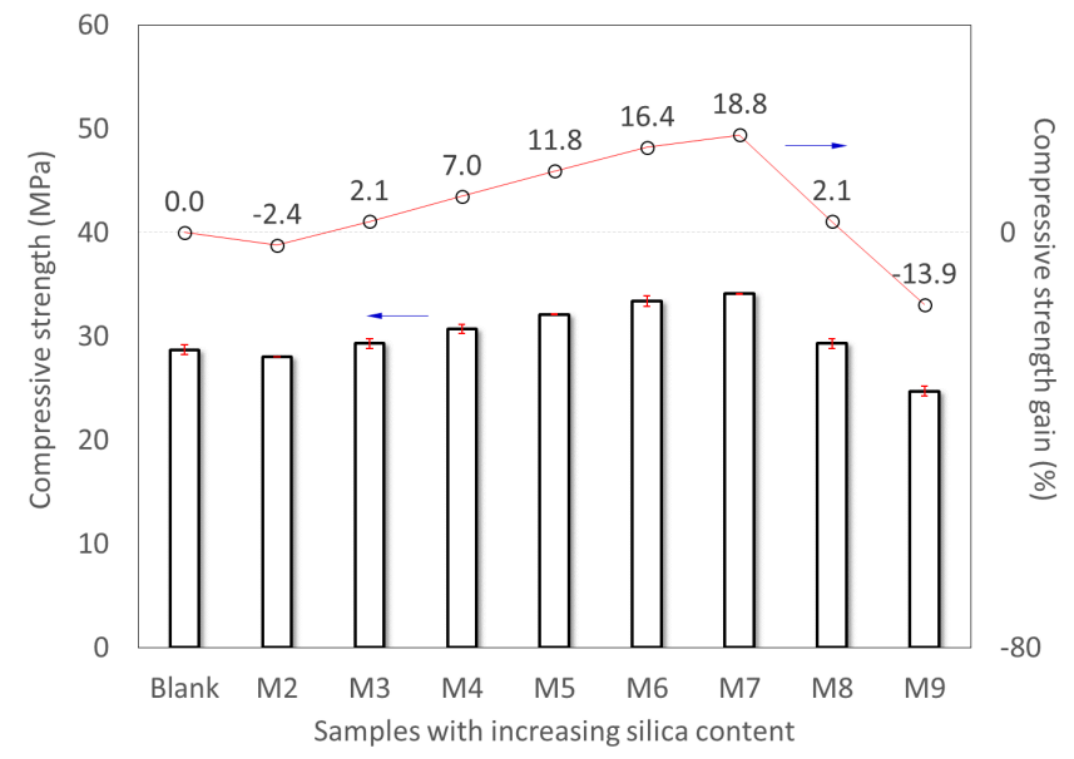

Figure. 18 Effect of silica loading to compressive strength of $\mathrm{CO}_{2}$ impregnated samples after 28 days in air curing.

According to the results of HSAM at 28 days compressive strength in air curing as shown in Figure. 18, it can be observed that the compressive strength of HSAM increased almost linearly from M4 to M7 by $7.09 \%, 11.70 \%, 16.38 \%$ and $18.70 \%$ respectively as compared to the control sample. The margin of compressive strength attainability of air-cured HSAM is acceptable in comparison with slightly higher attainability in water-cured HSAM due to the absence of water hydration. As compared to HSAM M7 at 7 days with compressive strength gain of $35.39 \%$, the compressive strength gain at 28 days is less significant with the highest at M7 with $16.38 \%$. This can be due to the effect of the initial carbonation induced by silica aerogel diminished gradually after 7 days of the initial curing process. In spite of this, M2 sample did not show any beneficial effects in terms of compressive strength gain due to a small dosage of silica aerogel. M8 and M9 sample showed a similar negative 
trend in compressive strength, where M9 decreased by $-14.05 \%$ as compared to the blank sample.

\subsection{Comparison of Optimal Compressive Strength Results between Water-Cured and Air-Cured Mortar Samples}

From the above Figure. 19, it is clearly shown that the compressive strength of $\mathrm{CO} 2$ impregnated samples are higher than the blank samples in both water and air curing. At 7 days, the compressive strength of M7 with the most notable gain achieved $38.06 \%$ in water curing and $35.39 \%$ in air curing respectively compared to the blank sample. At 28 days, the compressive strength gain of the carbonated samples continued to increase with a less significant gain of $17.29 \%$ in water curing and $16.38 \%$ in air curing. This trend shows the beneficial effect of $\mathrm{CO} 2$ impregnation due to the accelerated carbonation effect induced by the carbon dioxide in carbonated silica on the initial curing process. The accelerated carbonation causes decreased in porosity and adjustment in the packing of molecules due to increased formation of $\mathrm{CaCO} 3$ in the mortars that agreed with the study done by Forood Torabian et al. (2016). In spite of this, the accelerated carbonation gradually diminished after 7 days of curing process that could be due to most of the $\mathrm{CO} 2$ molecules have been reacted in the early stage of the carbonation process. 


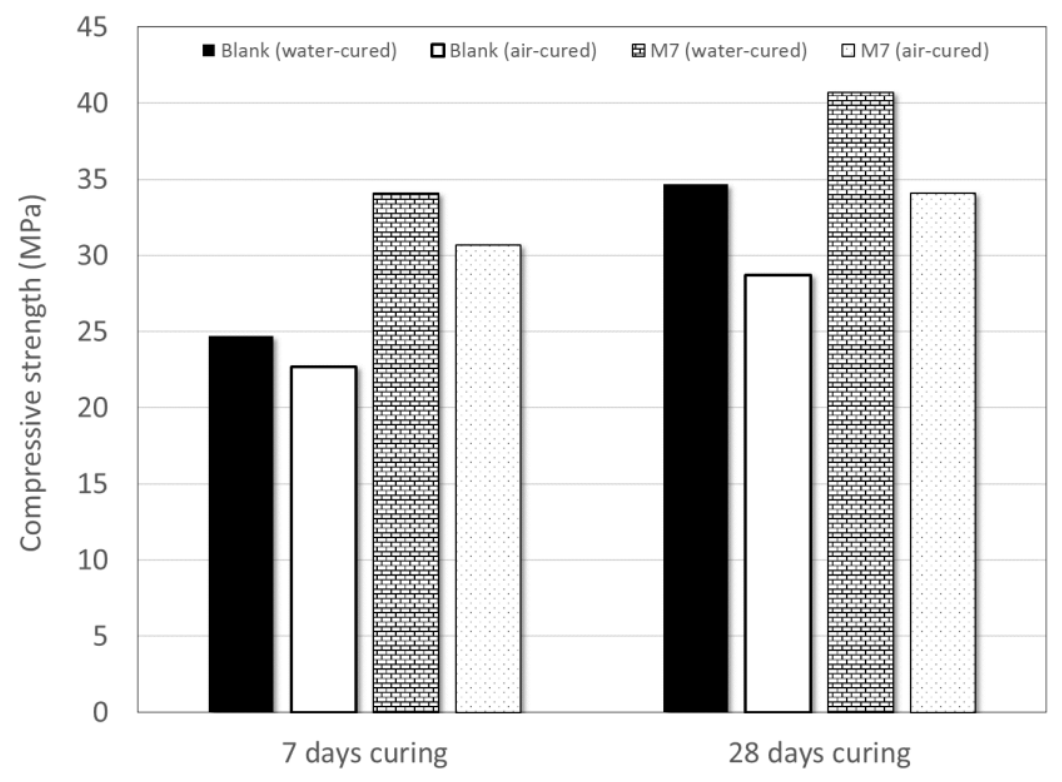

Figure. 19 Comparison of 7 days and 28 days Compressive Strength (MPa) of watercured and air-cured samples.

The most notable result of $38.06 \%$ with respect to blank sample was obtained in water cured M7 with $1.89 \%$ silica loading. This outcome indicates the relation of a higher amount of C-S-H formed as a consequence of silica addition. Silica fume, as well as other forms of nano silica, are classified as a highly reactive pozzolan and could react rapidly with calcium hydroxide $(\mathrm{CaOH})$ to form $\mathrm{C}-\mathrm{S}-\mathrm{H}$ gel as stated in the study done by J. Song and S. Liu. (2016). The formation of C-S-H gel, in addition, can further increase the mechanical properties of the mortar samples. However, the maximum compressive strength gain can only be achieved at the right amount of silica fume addition with the optimum water ratio.

The compressive strength development of HSAM samples containing carbonated silica aerogel fillers concluded to be higher than normal control samples due to the accelerated carbonation process, further supports the study done by Hanif et al. (2016) [29], on the utilization and enhancement of aerogel as cementitious composites. Due to 
the availability of $\mathrm{CO} 2$ molecules, the accelerated carbonation process formed dense $\mathrm{CaCO} 3$ in the cement matrix and reduced the overall porosity of the mortars. Besides, the pozzolanic effect from silica aerogel addition could replace dense crystals of calcium hydroxide $(\mathrm{CaOH})$ with a high density of $\mathrm{C}-\mathrm{S}-\mathrm{H}$ gel in the matrix as exemplified by the study done by Zaidi et al. (2019) [30]. These attributes have been shown to improve and develop the overall compressive strength of the mortar samples. However, it should be noted that the maximum compressive strength can only be achieved with the right amount of silica aerogel addition and the optimum water ratio. Based on that, the HSAM containing $1.89 \%$ indicated as the most optimum aerogel loading with the highest percentage gain in compressive strength for both water and air curing at all ages.

\subsection{Scanning Electron Microscope (SEM) and Electron Dispersive X-Ray (EDX)}

\section{Analysis}

The SEM imaging was carried out on the fractured surfaces of the samples after 28 days compressive strength tests with SEM magnification of x1000, x3000 and x10000. The SEM imaging for control blank and HSAM M7 samples are shown in Figure. 20 and Figure. 21 respectively. As discussed previously, HSAM M7 samples with $1.89 \%$ aerogel loading achieved the highest compressive strength gain exhibited dense and packed surface compared to the control samples due to accelerated carbonation reaction. In addition, at magnification x10000, HSAM M7 samples exhibited more uniform microstructure morphology with very less visible macro-pores as compared to the control samples as supported by the studies done by D. Fatima Julio et al. (2016) [31], which indicates overall porosity reduction due to the accelerated carbonation reaction induced by the carbonated silica aerogel addition. 


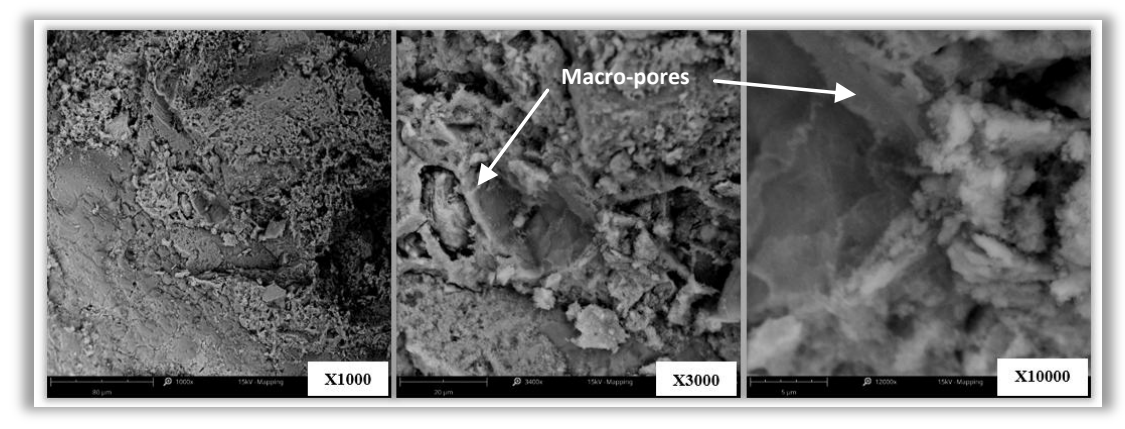

Figure. 20 : SEM Imaging of blank Sample from left x1000, x3000 and x10000 magnification.

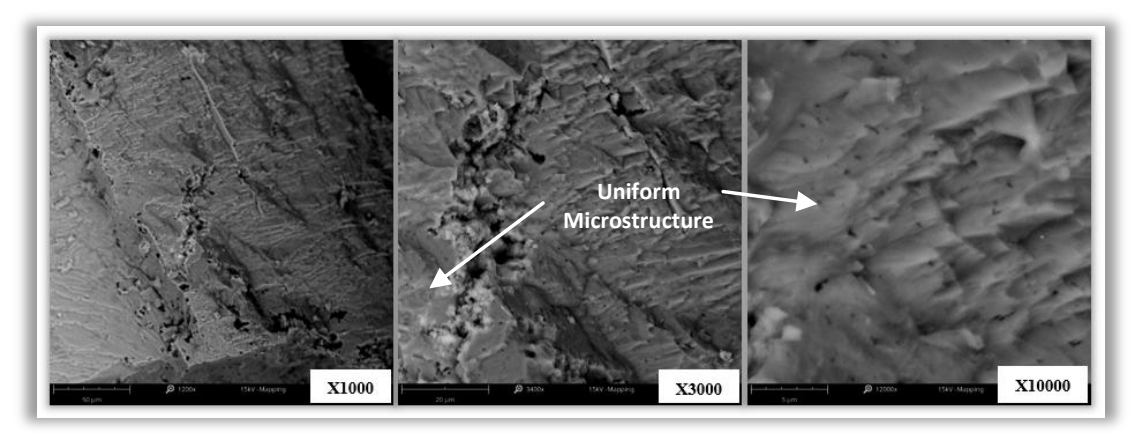

Figure.21: SEM Imaging of M7 Sample from left x1000, x3000 and x10000 magnification.

Energy dispersive X-ray (EDX) analysis was conducted on the blank and M7 samples to investigate and compare the composition fraction of the samples generated at 10000x of magnification SEM. The EDX analysis for blank and M7 samples are depicted in Figure. 22 and Figure. 23 respectively. Four element compositions were identified namely oxygen $(\mathrm{O})$, carbon $(\mathrm{C})$, silicon $(\mathrm{Si})$ and calcium $(\mathrm{Ca})$ with oxygen exhibits the highest weight concentration in both of the samples. As a comparison, the silicon composition shown in M7 sample is $25.31 \%$ of total weight concentration whereas in the blank sample is $13.29 \%$ of total weight concentration. The difference in the silicon composition clearly indicates that the M7 sample contains additional silica fume with reference to the blank sample. The higher content also indirectly proved 
that more carbonated structure is present in M7 sample as a result of carbonation using $\mathrm{CO} 2$ impregnation.

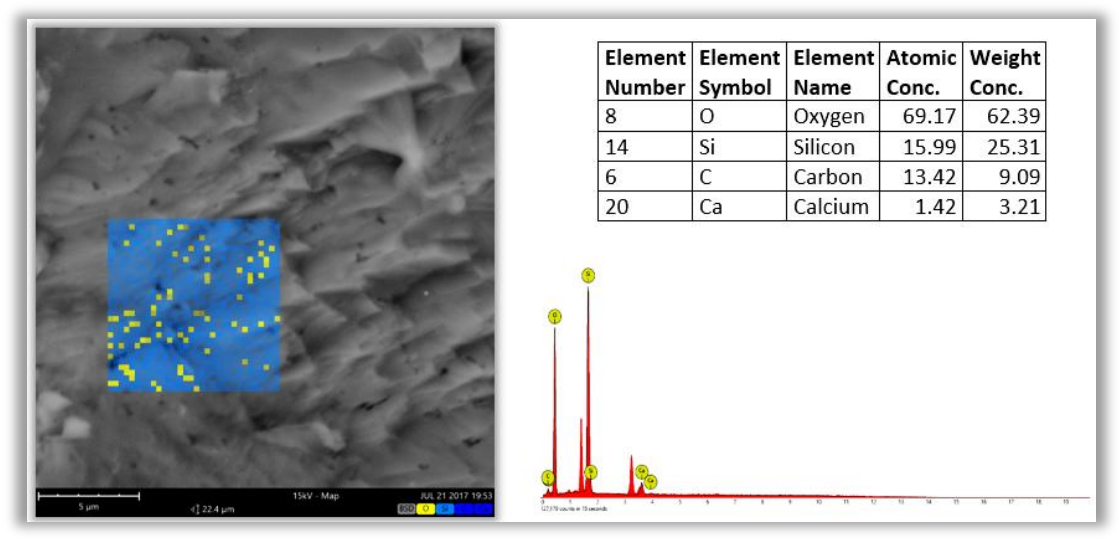

Figure. 24: EDX results of blank sample.

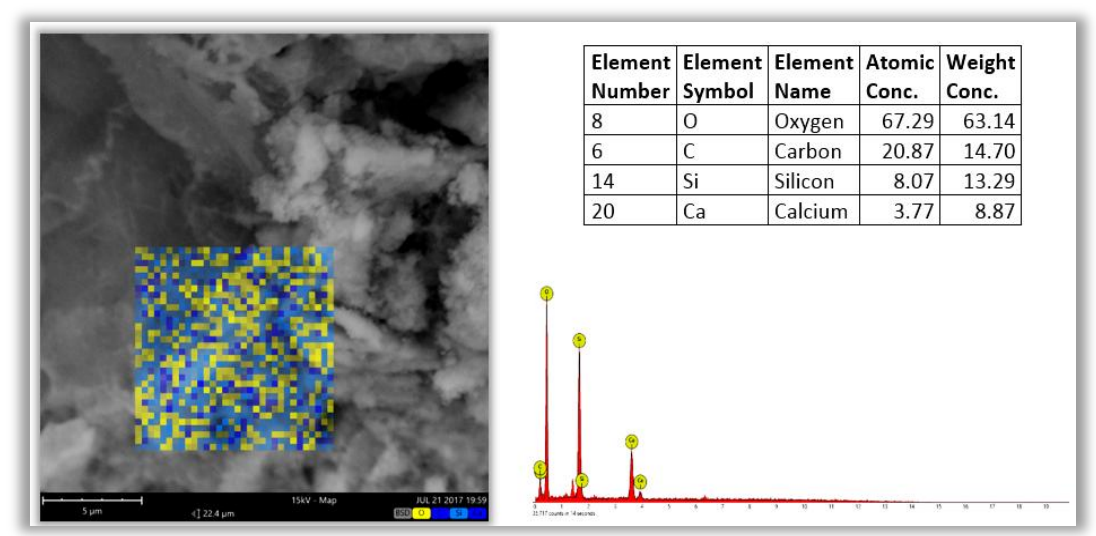

Figure.25: EDX results of M7 sample

\section{Limitations and practical use}

The addition of carbonated silica aerogel (CSA) in fresh concrete increases the carbonation as well as starts happening much earlier decreasing the $\mathrm{pH}$ value than in concrete without CSA, causing instability of the protective layer The $\mathrm{pH}$ value decreases in significant amount causing corrosion to start much earlier with the 
influence of chloride ions in the mortar. The requirement of $\mathrm{Cl}^{-}$ions to initiate the corrosion is about 7000 to $8000 \mathrm{ppm}$ at $12-13 \mathrm{pH}$ value but at $10-11$ the requirement is as low as $100 \mathrm{ppm}$ [32]. While slightly lower values of free $\mathrm{Cl}^{-}$contents occur for carbonated concrete compared to un-carbonated, a remarkable decrease in the chloride threshold value of steel corrosion, i.e., ratio of free $\mathrm{Cl}^{-}$to $\mathrm{pH}$ value or hydroxyl ion, is caused by the carbonation reaction. Thus, concrete after carbonation has a higher risk of steel corrosion initiation [33]. The practical use of this method is limited to:

- Dense concrete with low water to binder ratio (w/b) design.

- Ordinary Portland Cement (CEM I) binder type.

- Incorporate mineral admixtures reducing the free $\mathrm{Cl}^{-}$diffusion coefficient and increase $\mathrm{pH}$.

The main parameters that influence the corrosion rate of steel in carbonated mortar and concrete are the exposure conditions, the type of binder and the water/binder ratio [34]. decrease in w/b ratio corresponds to a reduction in corrosion rate of the embedded steel in carbonated mortar or concrete, for example a decrease of w/b from 0.8 to 0.55 led to a decrease from $2 \mu \mathrm{A} / \mathrm{cm}^{2}$ to $0.8 \mu \mathrm{A} / \mathrm{cm}^{2}$ ( 2.5 times), at $100 \% \mathrm{RH}$ [34],[35].Thus lower water to binder ratio must be adapted.

- The corrosion rate of reinforcing steel in carbonated mortar or concrete has been studied in many works only for Ordinary Portland Cement (CEM I).The main finding reported by the researchers is that the corrosion rate of steel in carbonated mortar or concrete increases for clinker replaced binders [34]. The use of blended materials in Portland cement as: slag, Fly ash or pozzolans, affects, in spite of others parameters, to 
the alkaline content which results from the hydration process. Therefore, the amount of carbonatable material is lesser in blended cements than in Portland ones [36].

\section{Conclusion}

This experiment investigated the effect of $\mathrm{CO} 2$ impregnation on the compressive strength of cement mortars with various silica loading from $0.55 \%$ to $2.42 \%$ by weight. In addition, the compressive strength of carbonated silica and un-carbonated silica were investigated. From the results, the following conclusions can be drawn:

1. The surface nature (hydrophobic or hydrophilic) of the silica fume significantly affect the compressive strength of the cement mortars. Silica fume was able to mix well with the cement mortar, producing homogenous mix while hydrophobic silica was unable to create a homogenous mix with the cement mortar due to its water repelling effect and therefore results drop in the compressive strength.

2. The effectiveness of carbonated silica incorporation was proven compared to uncarbonated silica incorporation in cement mortars. Uncarbonated silica (without $\mathrm{CO} 2$ exposure) did not show significant beneficial effects in terms of compressive strength gain with only a slight increment (less than 5\%) due to the presence of additional silica produces a higher amount of C-S-H in the cement mortars.

3. The beneficial effects of carbonated silica incorporation on compressive strength in water curing condition were demonstrated with the highest compressive strength gain of a sample containing $1.89 \%$ silica by weight. By the incorporation of $1.89 \%$ silica fume, compressive strength gain of $38.06 \%$ at 7 days curing age and $17.29 \%$ at 28 days curing age was achieved.

4. The beneficial effects of carbonated silica fume incorporation on compressive strength in ambient air curing condition were demonstrated with the highest compressive strength gain of a sample containing $1.89 \%$ silica by weight. By the incorporation of $1.89 \%$ silica fume, compressive strength gain of $35.39 \%$ at 7 days curing age and $18.70 \%$ at 28 days curing age was achieved.

5. CO2 impregnated samples in both different curing condition achieved compressive strength gain up to $38.06 \%$ for water-cured and $35.39 \%$ for air-cured due to the 
accelerated carbonation effect induced by the carbon dioxide in the carbonated silica on the initial curing process.

6. The strength development in HSAM in both different curing conditions was higher at 7 days whereby the carbonation reaction occurred more rapidly due to the availability of $\mathrm{CO} 2$ in the silica aerogel and gradually diminished after 7 days of curing process that could be due to most of the $\mathrm{CO} 2$ molecules have been reacted in the early stage of carbonation process.

7. Compressive strength gain in air-cured samples was slightly lower than water-cured samples due to the absence of water hydration. Aforementioned, the margin of compressive strength attainability of air-cured samples is acceptable in comparison with slightly higher attainability in water-cured samples.

8. The incorporation of silica more than $1.89 \%$ by weight resulted in a negative effect on the compressive strength gain in both water-cured and air-cured samples. By the incorporation of $2.42 \%$, the $\mathrm{CO} 2$ impregnated samples showed a drop in compressive strength of $21.46 \%$ at 7 days and $17.29 \%$ at 28 days for water-cured samples, $17.62 \%$ at 7 days and $14.05 \%$ at 28 days for air-cured samples.

\section{REFERENCES}


[1] Taniguchi N. On the basic concept of Nano-technology. In: Proceedings of International Conference on Production Engineering Tokyo, Part II. Japan Society of Precision Engineering; 1974. p. 18-23.

[2] A Porro , J S Dolado, I Campillo, E Erkizia , Y de Miguel, Y Saez de Ibarra, A Ayuela. Effects of nanosilica additions on cement pastes. In: Proceedings of the international conference on applications of nanotechnology in concrete design; 2005. p. 87- 96.

[3] Dortech, A. S \& Abbasi M. Silica Aerogel; synthesis, properties and characterization, Journal of Materials Processing Technology, 199. p. 1026.4

[4] C. Buratti, E. Moretti, E. Belloni, F. Agosti, Development of innovative aerogel based plasters: preliminary thermal and acoustic performance evaluation, Sustainability, 2014, 5839 - 5852.

[5] M. Arandigoyen, B. Bicer-Simsir, J.I. Alvarez, D.A. Lange, Variation of microstructure with carbonation in lime and blended pastes, Appl. Surf. Sci. 252 (20), 2006, $7562-7571$.

[6] J. M. Chi, R. Huang, and C. C. Yang, "Effects of carbonation on mechanical properties and durability of concrete using accelerated testing method," Journal of Marine Science and Technology, 2002, vol. 10, no. 1, pp. 14-20.

[7] G.W. Groves, A. Brough, I.G. Richardson, C.M. Dobson, Progressive changes in the structure of hardened $\mathrm{C} 3 \mathrm{~S}$ cement pastes due to carbonation, J. Am.Ceram. Soc. 74 (11), 1991, 2891-2896.

[8] G. Rimmelé, V. Barlet-Gouédard, O. Porcherie, B. Goffé, F. Brunet, Heterogeneous porosity distribution in Portland cement exposed to CO2rich fluids, Cem. Concr. Res. 38 (8), 2014.

[9] J. B. Aguiar and C. Júnior, "Carbonation of surface protected concrete," Construction and Building Materials, 2013, vol. 49, pp. 478-483. 
[10] St. John, D.A., Poole, A.B., \& Sims, I. The appearance and texture of concrete. Chapter 5 of Concrete petrography - A handbook of investigative techniques: 1998, 205-214.

[11] Sagüés, A.A., Moreno, E.I., Morris, W., \& Andrade, C. Carbonation in concrete and effect on steel corrosion. Springfield, VA, USA: National Technical Information Service, US Department of Commerce, 1997.

[12] Shaikh Hussain, Dipendu Bhunia, Shamsher B. Singh. An experimental investigation of Accelerated Carbonation on Properties of Concrete. 2015.

[13] J. B. Aguiar and C. Júnior, "Carbonation of surface protected concrete," Construction and Building Materials, 2013, vol. 49, pp. 478-483.

[14] C.L. Page and O. Vennesland, Pore solution composition and chloride binding capacity of silica fume cement pastes, Material Structures, 1983, Vol 16, pp 19-25.

[15] M. Pourbaix, Atlas of electrochemical equilibria in aqueous solutions. 2d English ed. 1974, Houston, Tex.: National Association of Corrosion Engineers.

[16] Parrott L.J., "A review of carbonation in reinforced concrete", Cement and Concrete Association, 1987, 369 pp.

[17] Parrott, RILEM Draft Recommendation CPC-18, Measurement of hardened concrete carbonation depth, Material structures, 1984, Vol. 17, pp. $434-440$.

[18] C. Buratti, E. Moretti, E. Belloni, F. Agosti, Development of innovative aerogel based plasters: preliminary thermal and acoustic performance evaluation, Sustainability, 2014, 5839 - 5852.

[19] Z. Liang, B. Fadhel, C.J. Schneider, A.L. Chaffee, Micropor. Mesopor. Mater. 111, 2008, pg 536.

[20] S. Cui, W. Cheng, X. Shen, M. Fan, A. Russell, Z. Wu, X. Yi, Energy Environ. Sci. 4, 2011, 2070.

[21] Nick Linnen, Robert Pfeffer, Y. S. Lin. CO2 capture using particulate silica aerogel immobilized with tetraethylenepentamine, Microporous and Mesoporous Materials 176, 2013, 123-131. 
[22] A. Samanta, A. Zhao, G.K.H. Shimizu, P. Sarkar, R. Gupta, Ind. Eng. Chem. Res. 51, 2012, 1438.

[23] Forood Torabian Isfahani, Elena Redaelli, Federica Lollini, Weiwen Li, and Luca Bertolini. Effects of Nanosilica on Compressive Strength and Durability Properties of Concrete with Different Water to Binder Ratios. Advances in Materials Science and Engineering, Volume 2016, pg 16.

[24] Tao Gao, Linn Ingunn Christie Sandberg, B Petter Jelle , Arild Gustavsen. Nano insulation materials for energy efficient buildings; Proceedings of Energy and Materials Research Conference. 2012, pg 376.

[25] Chen B, Fang C. Mechanical properties of EPS lightweight concrete. Construction Material 2011; 164: 173-80.

[26] Dorcheh, A. S. \& Abbasi M. H., Silica aerogel; synthesis, properties and characterization, Journal of Materials Processing Technology, 2008,199, pp. 10-26.

[27] Baetens R, Jelle BP, Gustavsen A. Aerogel insulation for building applications: a state of the art review. Energy Build 2011; 43:761-9.

[28] Serina Ng, Bjørn PetterJelle, Linn Ingunn Christie Sandbergb, TaoGaoc , Ólafur Haralds Wallevikad. Experimental investigations of aerogelincorporated ultra-high performance concrete. Construction and Building Materials 77, 2015,pg 307-316.

[29] Hanif, Diao, S., Lu, Z., Fan, T., \& Li, Z. Green lightweight cementitious composite incorporating aerogels and fly ash cenospheres - Mechanical and thermal insulating properties. Construction and Building Materials, 2016, 116, $422-430$.

[30] Zaidi, A. K. A. A., Demirel, B., \& Atis, C. D. Effect of different storage methods on thermal and mechanical properties of mortar containing aerogel, fly ash and nano-silica. Construction and Building Materials, 2019, 199, 501507.

[31] Mariade Fátima Júlio, António Soares, Laura M.Ilharco, InêsFlores-Colen, Jorgede Brito. Aerogel-based renders with lightweight aggregates: Correlation between molecular/pore structure and performance. Construction and Building Materials, 2016, 123, pp 485-495.

[32] Skokie, Illinois, Types and Causes of Concrete Deterioration, Portland Cement Association, 2002, page 4. 
[33] MingJin, SongGao, LinhuaJiang,HongqiangChu, MengtingLu, Fang FangZhi, Degradation of concrete with addition of mineral admixture due to free chloride ion penetration under the effect of carbonation, Corrosion science, volume 138,1 july 2018 , pages $42-53$

[34] M. Stefanoni, U. Angst, B. Elsener,Corrosion rate of carbon steel in carbonated concrete - A critical review,Cement and Concrete Research, Volume 103, 2018, Pages 35-48,

[35] Moreno, E. I., Cob-Sarabia, E., \& Borges, P. C. Corrosion Rates from Carbonated Concrete Specimens, (2004, January 1), NACE International.

[36] C. Alonso, C. Andrade Effect of cement type and cement proportion in the corrosion rate of rebars embedded in carbonates mortar Mater. Constr., 37 (205) (1987), pp. 5-15 